ORIGINAL ARTICLE

\section{Empagliflozin, Cardiovascular Outcomes, and Mortality in Type 2 Diabetes}

\author{
Bernard Zinman, M.D., Christoph Wanner, M.D., John M. Lachin, Sc.D., \\ David Fitchett, M.D., Erich Bluhmki, Ph.D., Stefan Hantel, Ph.D., \\ Michaela Mattheus, Dipl. Biomath., Theresa Devins, Dr.P.H., \\ Odd Erik Johansen, M.D., Ph.D., Hans J. Woerle, M.D., Uli C. Broedl, M.D., \\ and Silvio E. Inzucchi, M.D., for the EMPA-REG OUTCOME Investigators
}

A BSTRACT

BACKGROUND

The effects of empagliflozin, an inhibitor of sodium-glucose cotransporter 2, in addition to standard care, on cardiovascular morbidity and mortality in patients with type 2 diabetes at high cardiovascular risk are not known.

\section{METHODS}

We randomly assigned patients to receive $10 \mathrm{mg}$ or $25 \mathrm{mg}$ of empagliflozin or placebo once daily. The primary composite outcome was death from cardiovascular causes, nonfatal myocardial infarction, or nonfatal stroke, as analyzed in the pooled empagliflozin group versus the placebo group. The key secondary composite outcome was the primary outcome plus hospitalization for unstable angina.

\section{RESULTS}

A total of 7020 patients were treated (median observation time, 3.1 years). The primary outcome occurred in 490 of 4687 patients (10.5\%) in the pooled empagliflozin group and in 282 of 2333 patients (12.1\%) in the placebo group (hazard ratio in the empagliflozin group, 0.86 ; $95.02 \%$ confidence interval, 0.74 to 0.99 ; $\mathrm{P}=0.04$ for superiority). There were no significant between-group differences in the rates of myocardial infarction or stroke, but in the empagliflozin group there were significantly lower rates of death from cardiovascular causes $(3.7 \%$, vs. $5.9 \%$ in the placebo group; 38\% relative risk reduction), hospitalization for heart failure (2.7\% and $4.1 \%$, respectively; $35 \%$ relative risk reduction), and death from any cause $(5.7 \%$ and $8.3 \%$, respectively; $32 \%$ relative risk reduction). There was no significant between-group difference in the key secondary outcome $(\mathrm{P}=0.08$ for superiority). Among patients receiving empagliflozin, there was an increased rate of genital infection but no increase in other adverse events.

CONCLUSIONS

Patients with type 2 diabetes at high risk for cardiovascular events who received empagliflozin, as compared with placebo, had a lower rate of the primary composite cardiovascular outcome and of death from any cause when the study drug was added to standard care. (Funded by Boehringer Ingelheim and Eli Lilly; EMPA-REG OUTCOME ClinicalTrials.gov number, NCT01131676.)
From the Lunenfeld-Tanenbaum Research Institute, Mount Sinai Hospital (B.Z.) and the Divisions of Endocrinology (B.Z.) and Cardiology (D.F.), University of Toronto - all in Toronto; the Department of Medicine, Division of Nephrology, Würzburg University Clinic, Würzburg (C.W.), Boehringer Ingelheim Pharma, Biberach (E.B., S.H.), and Boehringer Ingelheim Pharma, Ingelheim (M.M., H.J.W., U.C.B.) - all in Germany; the Biostatistics Center, George Washington University, Rockville, MD (J.M.L.); Boehringer Ingelheim Pharmaceuticals, Ridgefield, CT (T.D.); Boehringer Ingelheim Norway, Asker, Norway (O.E.J.); and the Section of Endocrinology, Yale University School of Medicine, New Haven, CT (S.E.I.). Address reprint requests to $\mathrm{Dr}$. Zinman at Mount Sinai Hospital, 60 Murray St., Suite L5-024, Box 17, Toronto, ONT M5T 3L9, Canada, or at zinman@ lunenfeld.ca.

This article was published on September 17, 2015, at NEJM.org.

N Engl J Med 2015;373:2117-28. DOI: 10.1056/NEJMoa1504720

Coppright (๑) 2015 Massachusetts Medical Society. 
T YPE 2 DIABETES IS A MAJOR RISK FACTOR for cardiovascular disease, ${ }^{1,2}$ and the presence of both type 2 diabetes and cardiovascular disease increases the risk of death. ${ }^{3}$ Evidence that glucose lowering reduces the rates of cardiovascular events and death has not been convincingly shown, ${ }^{4-6}$ although a modest cardiovascular benefit may be observed after a prolonged follow-up period. ${ }^{7}$ Furthermore, there is concern that intensive glucose lowering or the use of specific glucose-lowering drugs may be associated with adverse cardiovascular outcomes. ${ }^{8}$ Therefore, it is necessary to establish the cardiovascular safety benefits of glucose-lowering agents. ${ }^{9}$

Inhibitors of sodium-glucose cotransporter 2 reduce rates of hyperglycemia in patients with type 2 diabetes by decreasing renal glucose reabsorption, thereby increasing urinary glucose excretion. ${ }^{10}$ Empagliflozin is a selective inhibitor of sodium glucose cotransporter $2^{11}$ that has been approved for type 2 diabetes. ${ }^{12}$ Given as either monotherapy or as an add-on therapy, the drug is reported to reduce glycated hemoglobin levels in patients with type 2 diabetes, including those with stage 2 or 3a chronic kidney disease. ${ }^{13-20}$ Furthermore, empagliflozin is associated with weight loss and reductions in blood pressure without increases in heart rate. ${ }^{13-20}$ Empagliflozin also has favorable effects on markers of arterial stiffness and vascular resistance, ${ }^{21}$ visceral adiposity, ${ }^{22}$ albuminuria, ${ }^{20}$ and plasma urate. ${ }^{13-19}$ Empagliflozin has been associated with an increase in levels of both low-density lipoprotein (LDL) ${ }^{14}$ and high-density lipoprotein (HDL) cholesterol. ${ }^{13-16}$ The most common side effects of empagliflozin are urinary tract infection and genital infection. ${ }^{12}$

In the EMPA-REG OUTCOME trial, we examined the effects of empagliflozin, as compared with placebo, on cardiovascular morbidity and mortality in patients with type 2 diabetes at high risk for cardiovascular events who were receiving standard care.

\section{METHODS}

STUDY OVERSIGHT

The trial was designed and overseen by a steering committee that included academic investigators and employees of Boehringer Ingelheim. The role of Eli Lilly was limited to cofunding the trial. Safety data were reviewed by an independent aca- demic data monitoring committee every 90 days or at the discretion of the committee. Cardiovascular outcome events and deaths were prospectively adjudicated by two clinical-events committees (one for cardiac events and the other for neurologic events), as recommended by the Food and Drug Administration (FDA) guidelines. ${ }^{9} \mathrm{~A}$ list of investigators and committee members is provided in Sections A and B, respectively, in the Supplementary Appendix, which is available with the full text of this article at NEJM.org.

The trial was conducted in accordance with the principles of the Declaration of Helsinki and the the International Conference on Harmonisation Good Clinical Practice guidelines and was approved by local authorities. An independent ethics committee or institutional review board approved the clinical protocol at each participating center. All the patients provided written informed consent before study entry.

All the authors were involved in the study design and had access to the data, which were analyzed by one of the study sponsors, Boehringer Ingelheim. All the authors vouch for the accuracy and completeness of the data analyses and for the fidelity of the study to the protocol, available at NEJM.org. Members of the University of Freiburg conducted an independent statistical analysis of cardiovascular outcomes (Section B in the Supplementary Appendix). The manuscript was drafted by the first and last authors and revised by all the authors. Medical writing assistance, which was paid for by Boehringer Ingelheim, was provided by Fleishman-Hillard Group.

\section{STUDY DESIGN}

As described previously, ${ }^{23}$ this was a randomized, double-blind, placebo-controlled trial to assess the effect of once-daily empagliflozin (at a dose of either $10 \mathrm{mg}$ or $25 \mathrm{mg}$ ) versus placebo on cardiovascular events in adults with type 2 diabetes at high cardiovascular risk against a background of standard care. Patients were treated at 590 sites in 42 countries. The trial continued until an adjudicated primary outcome event had occurred in at least 691 patients.

\section{STUDY PATIENTS}

Eligible patients with type 2 diabetes were adults ( $\geq 18$ years of age) with a body-mass index (the weight in kilograms divided by the square of the 
height in meters) of 45 or less and an estimated glomerular filtration rate (eGFR) of at least $30 \mathrm{ml}$ per minute per $1.73 \mathrm{~m}^{2}$ of body-surface area, according to the Modification of Diet in Renal Disease criteria. All the patients had established cardiovascular disease (as defined in Section C in the Supplementary Appendix) and had received no glucose-lowering agents for at least 12 weeks before randomization and had a glycated hemoglobin level of at least $7.0 \%$ and no more than $9.0 \%$ or had received stable glucose-lowering therapy for at least 12 weeks before randomization and had a glycated hemoglobin level of at least $7.0 \%$ and no more than $10.0 \%$. Other key exclusion criteria are provided in Section D in the Supplementary Appendix.

\section{STUDY PROCEDURES}

Eligible patients underwent a 2-week, open-label, placebo run-in period in which background glucose-lowering therapy was unchanged. Patients meeting the inclusion criteria were then randomly assigned in a 1:1:1 ratio to receive either $10 \mathrm{mg}$ or $25 \mathrm{mg}$ of empagliflozin or placebo once daily. Randomization was performed with the use of a computer-generated random-sequence and interactive voice- and Web-response system and was stratified according to the glycated hemoglobin level at screening ( $<8.5 \%$ or $\geq 8.5 \%$ ), bodymass index at randomization ( $<30$ or $\geq 30$ ), renal function at screening (eGFR, 30 to $59 \mathrm{ml}, 60$ to $89 \mathrm{ml}$, or $\geq 90 \mathrm{ml}$ per minute per $1.73 \mathrm{~m}^{2}$ ), and geographic region (North America [plus Australia and New Zealand], Latin America, Europe, Africa, or Asia).

Background glucose-lowering therapy was to remain unchanged for the first 12 weeks after randomization, although intensification was permitted if the patient had a confirmed fasting glucose level of more than $240 \mathrm{mg}$ per deciliter ( $>13.3 \mathrm{mmol}$ per liter). In cases of medical necessity, dose reduction or discontinuation of background medication could occur. After week 12, investigators were encouraged to adjust glucoselowering therapy at their discretion to achieve glycemic control according to local guidelines. Throughout the trial, investigators were encouraged to treat other cardiovascular risk factors (including dyslipidemia and hypertension) to achieve the best available standard of care according to local guidelines. Patients were instructed to attend the clinic at prespecified times, which included a follow-up visit 30 days after the end of treatment. Patients who prematurely discontinued a study drug were to be followed for ascertainment of cardiovascular outcomes, and attempts were made to collect vital-status information for any patient who was lost to follow-up, as allowed by local guidelines.

\section{STUDY OUTCOMES}

The primary outcome was a composite of death from cardiovascular causes, nonfatal myocardial infarction (excluding silent myocardial infarction), or nonfatal stroke. The key secondary outcome was a composite of the primary outcome plus hospitalization for unstable angina. Definitions of the major clinical outcomes are provided in Section E in the Supplementary Appendix.

Safety was assessed on the basis of adverse events that occurred during treatment or within 7 days after the last dose of a study drug and were coded with the use of the Medical Dictionary for Regulatory Activities, version 18.0. Adverse events of special interest included confirmed hypoglycemic adverse events (plasma glucose level, $\leq 70 \mathrm{mg}$ per deciliter [3.9 mmol per liter] or an event requiring assistance), and adverse events reflecting urinary tract infection, genital infection, volume depletion, acute renal failure, bone fracture, diabetic ketoacidosis, and thromboembolic events.

\section{STATISTICAL ANALYSIS}

The primary hypothesis was noninferiority for the primary outcome with empagliflozin (pooled doses of $10 \mathrm{mg}$ and $25 \mathrm{mg}$ ) versus placebo with a margin of 1.3 for the hazard ratio. ${ }^{9}$ We used a four-step hierarchical-testing strategy for the pooled empagliflozin group versus the placebo group in the following order: noninferiority for the primary outcome, noninferiority for the key secondary outcome, superiority for the primary outcome, and superiority for the key secondary outcome.

Since interim data from the trial were included in a new-drug application submitted to the FDA, under the Haybittle-Peto rule, a two-sided P value of 0.0498 or less was considered to indicate statistical significance in the final analyses. ${ }^{23}$ For the test of noninferiority for the primary outcome with a margin of 1.3 at a one-sided level of 0.0249 , at least 691 events were required to provide a power of at least $90 \%$ on the assumption of a true hazard ratio of 1.0. Noninferiority for 
the primary outcome was determined if the upper boundary of the two-sided $95.02 \%$ confidence interval was less than 1.3. Analyses were based on a Cox proportional-hazards model, with study group, age, sex, baseline body-mass index, baseline glycated hemoglobin level, baseline eGFR, and geographic region as factors. Estimates of cumulative-incidence function were corrected for death as a competing risk, ${ }^{24}$ except for death from any cause, for which Kaplan-Meier estimates are presented. Because of the declining numbers of patients at risk, cumulative-incidence plots have been truncated at 48 months. We calculated the number of patients who would need to be treated to prevent one death on the basis of the exponential distribution.

We performed the primary analysis using a modified intention-to-treat approach among patients who had received at least one dose of a study drug. Data for patients who did not have an event were censored on the last day they were known to be free of the outcome. Secondary analyses included comparisons of the 10-mg dose of empagliflozin versus placebo and the $25-\mathrm{mg}$ dose versus placebo. Sensitivity analyses are described in the Section F in the Supplementary Appendix. We analyzed the changes from baseline in glycated hemoglobin level, weight, waist circumference, systolic and diastolic blood pressure, heart rate, LDL and HDL cholesterol, and uric acid using a repeated-measures analysis as a mixed model. Subgroup analyses are described in Section F in the Supplementary Appendix.

\section{RESULTS}

\section{STUDY PATIENTS}

A total of 7028 patients underwent randomization from September 2010 through April 2013. Of these patients, 7020 were treated and included in the primary analysis (Fig. S1 in Section $\mathrm{G}$ in the Supplementary Appendix). Reasons for premature discontinuation are provided in Table $\mathrm{S} 1$ in Section H in the Supplementary Appendix. Overall, $97.0 \%$ of patients completed the study, with $25.4 \%$ of patients prematurely discontinuing a study drug. Final vital status was available for $99.2 \%$ of patients.

At baseline, demographic and clinical characteristics were well balanced between the placebo group and the empagliflozin group (Table S2 in Section I in the Supplementary Appendix). Ac- cording to the inclusion criteria, more than $99 \%$ of patients had established cardiovascular disease, and patients were well treated with respect to the use of lipid-lowering therapy and antihypertensive medications at baseline. The median duration of treatment was 2.6 years, and the median observation time was 3.1 years; both durations were similar in the pooled empagliflozin group and the placebo group (Table S3 in Section $\mathrm{J}$ in the Supplementary Appendix).

\section{CARDIOVASCULAR OUTCOMES}

The primary outcome occurred in a significantly lower percentage of patients in the empagliflozin group (490 of 4687 [10.5\%]) than in the placebo group (282 of 2333 [12.1\%]) (hazard ratio in the empagliflozin group, 0.86; $95.02 \%$ confidence interval [CI], 0.74 to 0.99 ; $\mathrm{P}<0.001$ for noninferiority and $\mathrm{P}=0.04$ for superiority) (Fig. $1 \mathrm{~A}$ ). The key secondary outcome occurred in 599 of 4687 patients $(12.8 \%)$ in the empagliflozin group and 333 of 2333 patients $(14.3 \%)$ in the placebo group (hazard ratio, $0.89 ; 95 \% \mathrm{CI}, 0.78$ to 1.01 ; $\mathrm{P}<0.001$ for noninferiority and $\mathrm{P}=0.08$ for superiority).

As compared with placebo, empagliflozin resulted in a significantly lower risk of death from cardiovascular causes (hazard ratio, 0.62; 95\% CI, 0.49 to 0.77; P<0.001) (Fig. 1B), death from any cause (hazard ratio, 0.68 ; 95\% CI, 0.57 to $0.82, \mathrm{P}<0.001$; Fig. $1 \mathrm{C}$ ), and hospitalization for heart failure (hazard ratio, 0.65; 95\% CI, 0.50 to $0.85 ; \mathrm{P}=0.002$ ) (Fig. 1D). Hazard ratios for cardiovascular outcomes with empagliflozin versus placebo are shown in Table 1. Absolute reductions in incidence rates for cardiovascular outcomes are provided in Table S4 in Section K in the Supplementary Appendix. All categories of death from cardiovascular causes contributed to the reduction in cardiovascular death in the empagliflozin group (Table S5 in Section L in the Supplementary Appendix). There were no significant between-group differences in the occurrence of myocardial infarction or stroke (Table 1). Myocardial infarction was reported in $4.8 \%$ of patients in the empagliflozin group and $5.4 \%$ of those in the placebo group, and stroke in $3.5 \%$ and $3.0 \%$ of patients, respectively.

For the primary and key secondary outcomes, hazard ratios for the comparison between the 10-mg dose of empagliflozin versus placebo and the 25-mg dose versus placebo were virtually 


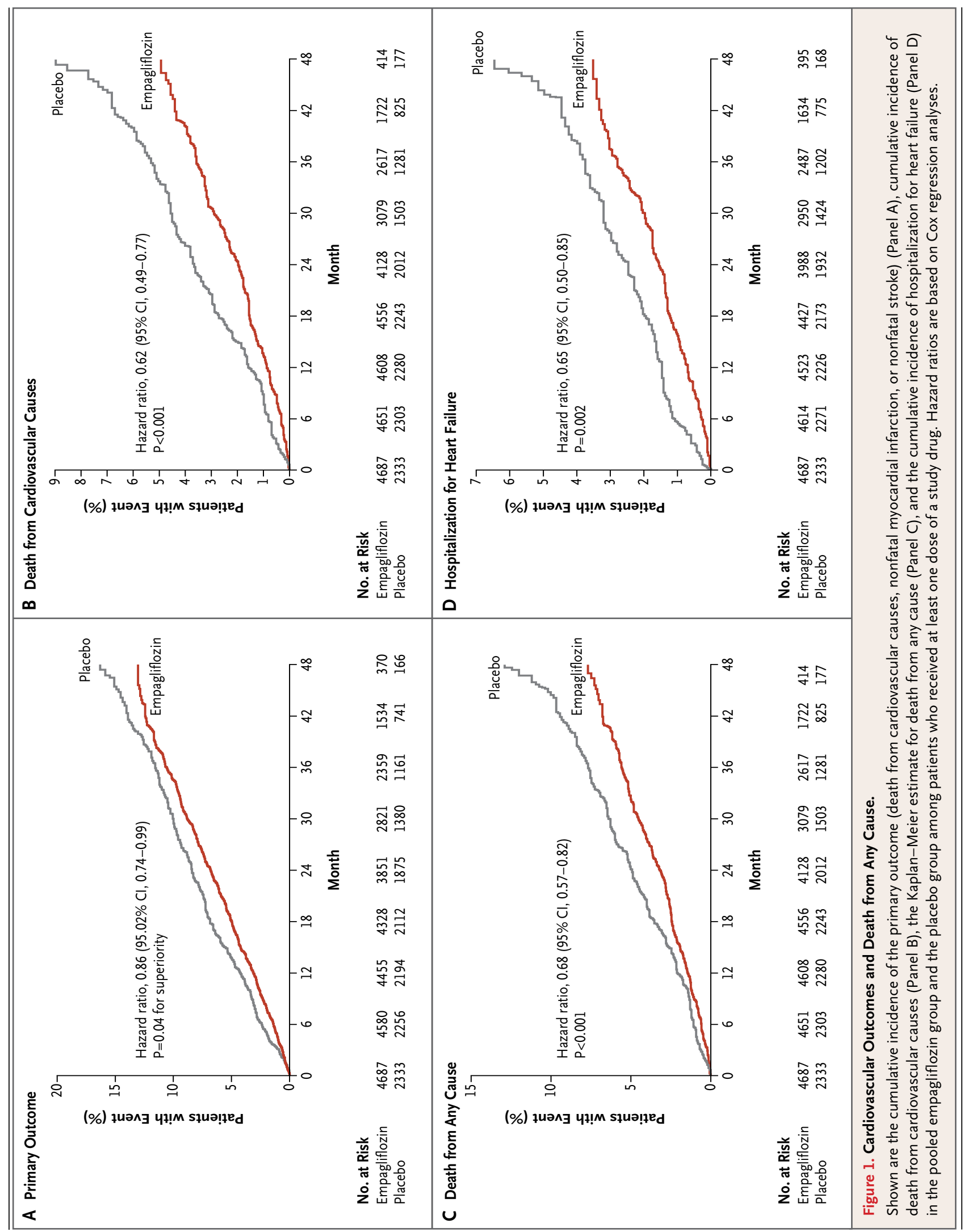

N ENGLJ MED 373;22 NEJM.ORG NOVEMBER 26, 2015

The New England Journal of Medicine 


\begin{tabular}{|c|c|c|c|c|c|c|}
\hline \multirow[t]{2}{*}{ Outcome } & \multicolumn{2}{|c|}{$\begin{array}{l}\text { Placebo } \\
(\mathrm{N}=2333)\end{array}$} & \multicolumn{2}{|c|}{$\begin{array}{l}\text { Empagliflozin } \\
\qquad(\mathrm{N}=4687)\end{array}$} & \multirow[t]{2}{*}{$\begin{array}{l}\text { Hazard Ratio } \\
\qquad(95 \% \mathrm{Cl})\end{array}$} & \multirow[t]{2}{*}{ P Value } \\
\hline & no. (\%) & $\begin{array}{l}\text { rate } / 1000 \\
\text { patient-pr }\end{array}$ & no. (\%) & $\begin{array}{l}\text { rate } / 1000 \\
\text { patient- } y r\end{array}$ & & \\
\hline $\begin{array}{l}\text { Death from cardiovascular causes, nonfatal myocar- } \\
\text { dial infarction, or nonfatal stroke: primary } \\
\text { outcome* }\end{array}$ & $282(12.1)$ & 43.9 & $490(10.5)$ & 37.4 & $0.86(0.74-0.99)$ & \\
\hline Noninferiority & & & & & & $<0.001 \uparrow$ \\
\hline Superiority & & & & & & $0.04 \uparrow$ \\
\hline $\begin{array}{l}\text { Death from cardiovascular causes, nonfatal myo- } \\
\text { cardial infarction, nonfatal stroke, or hospi- } \\
\text { talization for unstable angina: key secondary } \\
\text { outcome* }\end{array}$ & $333(14.3)$ & 52.5 & $599(12.8)$ & 46.4 & $0.89(0.78-1.01)$ & \\
\hline Noninferiority & & & & & & $<0.001 \uparrow$ \\
\hline Superiority & & & & & & $0.08 \dagger$ \\
\hline \multicolumn{7}{|l|}{ Death } \\
\hline From any cause & $194(8.3)$ & 28.6 & $269(5.7)$ & 19.4 & $0.68(0.57-0.82)$ & $<0.001$ \\
\hline From cardiovascular causes & $137(5.9)$ & 20.2 & $172(3.7)$ & 12.4 & $0.62(0.49-0.77)$ & $<0.001$ \\
\hline $\begin{array}{l}\text { Fatal or nonfatal myocardial infarction excluding } \\
\text { silent myocardial infarction }\end{array}$ & $126(5.4)$ & 19.3 & $223(4.8)$ & 16.8 & $0.87(0.70-1.09)$ & 0.23 \\
\hline $\begin{array}{l}\text { Nonfatal myocardial infarction excluding silent } \\
\text { myocardial infarction }\end{array}$ & $121(5.2)$ & 18.5 & $213(4.5)$ & 16.0 & $0.87(0.70-1.09)$ & 0.22 \\
\hline Silent myocardial infarction & $15(1.2)$ & 5.4 & $38(1.6)$ & 7.0 & $1.28(0.70-2.33)$ & 0.42 \\
\hline Hospitalization for unstable angina & $66(2.8)$ & 10.0 & $133(2.8)$ & 10.0 & $0.99(0.74-1.34)$ & 0.97 \\
\hline Coronary revascularization procedure & $186(8.0)$ & 29.1 & $329(7.0)$ & 25.1 & $0.86(0.72-1.04)$ & 0.11 \\
\hline Fatal or nonfatal stroke & $69(3.0)$ & 10.5 & $164(3.5)$ & 12.3 & $1.18(0.89-1.56)$ & 0.26 \\
\hline Nonfatal stroke & $60(2.6)$ & 9.1 & $150(3.2)$ & 11.2 & $1.24(0.92-1.67)$ & 0.16 \\
\hline Transient ischemic attack & $23(1.0)$ & 3.5 & $39(0.8)$ & 2.9 & $0.85(0.51-1.42)$ & 0.54 \\
\hline Hospitalization for heart failure & $95(4.1)$ & 14.5 & $126(2.7)$ & 9.4 & $0.65(0.50-0.85)$ & 0.002 \\
\hline $\begin{array}{c}\text { Hospitalization for heart failure or death from car- } \\
\text { diovascular causes excluding fatal stroke }\end{array}$ & $198(8.5)$ & 30.1 & $265(5.7)$ & 19.7 & $0.66(0.55-0.79)$ & $<0.001$ \\
\hline
\end{tabular}

identical to those in the pooled analysis, but the individual dose effects were not significant, owing to the smaller numbers of outcome events in the individual groups (Table S6 and Fig. S2 in Section $M$ in the Supplementary Appendix). The hazard ratios for the primary outcome were 0.85 (95\% CI, 0.72 to $1.01 ; \mathrm{P}=0.07$ ) for the $10-\mathrm{mg}$ dose of empagliflozin versus placebo and 0.86 (95\% CI, 0.73 to $1.02 ; \mathrm{P}=0.09$ ) for the $25-\mathrm{mg}$ dose versus placebo.

In subgroup analyses, there was some hetero- geneity for the primary outcome. In contrast, there was a consistent benefit of empagliflozin versus placebo on death from cardiovascular causes across all subgroups (Fig. 2, and Tables $\mathrm{S} 7$ and S8 in Section $\mathrm{N}$ in the Supplementary Appendix).

In prespecified sensitivity analyses based on events that occurred within 30 days after last dose of a study drug, results for the primary outcome, cardiovascular death, myocardial infarction, and stroke were consistent with the 
primary analyses, and the point estimate for the hazard ratio for stroke was closer to 1.00 (Tables S9 and S10 in Section O in the Supplementary Appendix). A sensitivity analysis of death from any cause in which it was assumed that all patients who were lost to follow-up in the empagliflozin group died and all patients who were lost to follow-up in the placebo group were alive showed a significant benefit of empagliflozin versus placebo (hazard ratio, 0.77; 95\% CI, 0.65 to $0.93 ; \mathrm{P}=0.005$ ).

\section{GLYCEMIC CONTROL}

After 12 weeks, during which glucose-lowering therapy was to remain unchanged, the adjusted mean differences in the glycated hemoglobin level between patients receiving empagliflozin and those receiving placebo were -0.54 percentage points $(95 \% \mathrm{CI},-0.58$ to -0.49 ) in the $10-\mathrm{mg}$ group and -0.60 percentage points $(95 \% \mathrm{CI}$, -0.64 to -0.55 ) in the $25-\mathrm{mg}$ group (Fig. 3). At week 94, the adjusted mean differences in the glycated hemoglobin level between patients receiving empagliflozin and those receiving placebo were -0.42 percentage points $(95 \% \mathrm{CI}$, -0.48 to -0.36 ) and -0.47 percentage points (95\% CI, -0.54 to -0.41 ), respectively; at week 206, the differences were -0.24 percentage points $(95 \% \mathrm{CI},-0.40$ to -0.08$)$ and -0.36 percentage points ( $95 \% \mathrm{CI},-0.51$ to -0.20 ).

\section{CARDIOVASCULAR RISK FACTORS}

Over the course of the study, empagliflozin, as compared with placebo, was associated with small reductions in weight, waist circumference, uric acid level, and systolic and diastolic blood pressure with no increase in heart rate and small increases in both LDL and HDL cholesterol (Fig. S3 in Section P in the Supplementary Appendix). A higher percentage of patients in the placebo group received additional glucose-lowering medications (including sulfonylurea and insulin), antihypertensive medications (including diuretics), and anticoagulants during the trial, with no between-group difference in the receipt of lipidlowering drugs (Tables S11 and S12 in Section Q in the Supplementary Appendix).

\section{SAFETY AND ADVERSE EVENTS}

The proportions of patients who had adverse events, serious adverse events, and adverse events leading to the discontinuation of a study drug were similar in the empagliflozin group and the placebo group (Table 2). Genital infection was reported in a higher percentage of patients in the pooled empagliflozin group. The proportions of patients with confirmed hypoglycemic adverse events, acute renal failure, diabetic ketoacidosis, thromboembolic events, bone fracture, and events consistent with volume depletion were similar in the two study groups. Urosepsis was reported in $0.4 \%$ of patients in the empagliflozin group and $0.1 \%$ of those in the placebo group, but there was no imbalance in overall rates of urinary tract infection, complicated urinary tract infection, or pyelonephritis (Table S13 in Section $\mathrm{R}$ in the Supplementary Appendix). Clinical laboratory data are provided in Table S14 in Section S in the Supplementary Appendix. There were no relevant changes in electrolytes in the two study groups. Hematocrit values were higher in the empagliflozin groups than in the placebo group (mean $[ \pm S D]$ changes from baseline, $4.8 \pm 5.5 \%$ in the group receiving $10 \mathrm{mg}$ of empagliflozin, $5.0 \pm 5.3 \%$ in the group receiving $25 \mathrm{mg}$ of empagliflozin, and $0.9 \pm 4.7 \%$ in the placebo group).

\section{DISCUSSION}

Among patients with type 2 diabetes at high risk for cardiovascular events, those receiving empagliflozin had a lower rate of the primary composite outcome of death from cardiovascular causes, nonfatal myocardial infarction, or nonfatal stroke than did patients receiving placebo. The difference between empagliflozin and placebo was driven by a significant reduction in death from cardiovascular causes, with no significant between-group difference in the risk of myocardial infarction or stroke. Since the two groups had similar rates of hospitalization for unstable angina, there was no significant difference in the key secondary outcome, which included the risk of hospitalization for unstable angina. Patients in the empagliflozin group had significantly lower risks of death from any cause and for hospitalization for heart failure than did those in the placebo group.

Although a small dose-response effect for the 10-mg dose of empagliflozin versus placebo and the 25-mg dose versus placebo has been documented for metabolic responses, in our study the two dose groups had similar hazard 


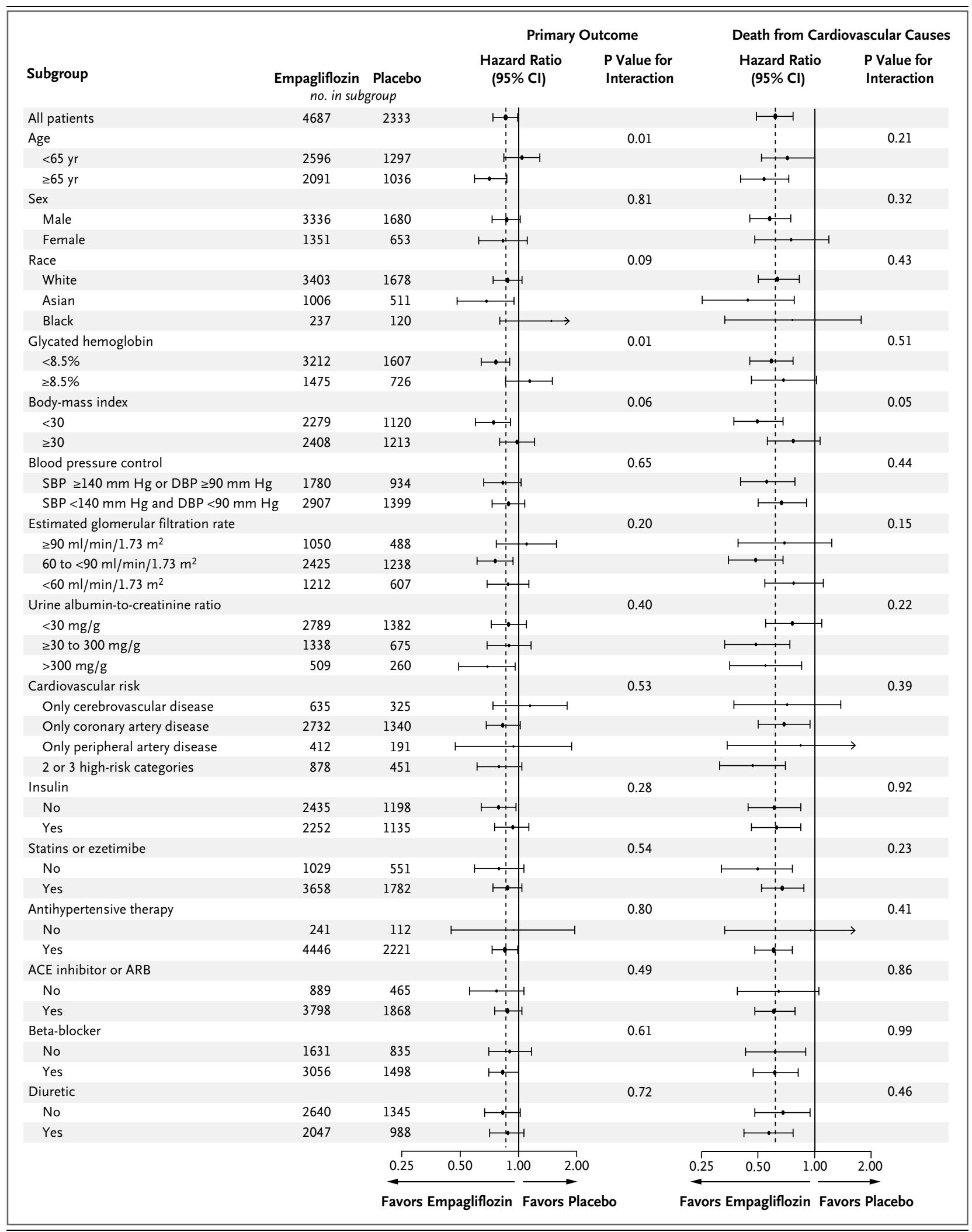


Figure 2 (facing page). Subgroup Analyses for the Primary Outcome and Death from Cardiovascular Causes.

Shown are the results of a prespecified Cox regression analysis of data for subgroups of patients with respect to the primary outcome. Subgroup analyses of death from cardiovascular causes were conducted post hoc. $P$ values are for tests of homogeneity of between-group differences among subgroups with no adjustment for multiple testing. The size of the ovals is proportional to the number of patients in the subgroup. ACE denotes angiotensin-converting enzyme, ARB angiotensin-receptor blocker, DBP diastolic blood pressure, and SBP systolic blood pressure.

ratios for cardiovascular outcomes. Thus, in clinical practice, the choice of the empagliflozin dose will probably depend primarily on the achievement of metabolic targets and the occurrence of adverse events.

These benefits were observed in a population with established cardiovascular disease in whom cardiovascular risk factors, including blood pressure and dyslipidemia, were well treated with the use of renin-angiotensin-aldosterone system inhibitors, statins, and acetylsalicylic acid. The reductions in the risk of cardiovascular death in the empagliflozin group were consistent across subgroups according to baseline characteristics.

Notably, reductions in the risks of death from cardiovascular causes and from any cause occurred early in the trial, and these benefits continued throughout the study. The relative reduction of $32 \%$ in the risk of death from any cause in the pooled empagliflozin group means that 39 patients (41 in the 10-mg group and 38 in the 25-mg group) would need to be treated during a 3-year period to prevent one death, but these numbers cannot be extrapolated to patient populations with other clinical characteristics.

Even though investigators were encouraged to adjust glucose-lowering therapy according to local guidelines, many patients did not reach their glycemic targets, with an adjusted mean glycated hemoglobin level at week 206 of 7.81\% in the pooled empagliflozin group and $8.16 \%$ in the

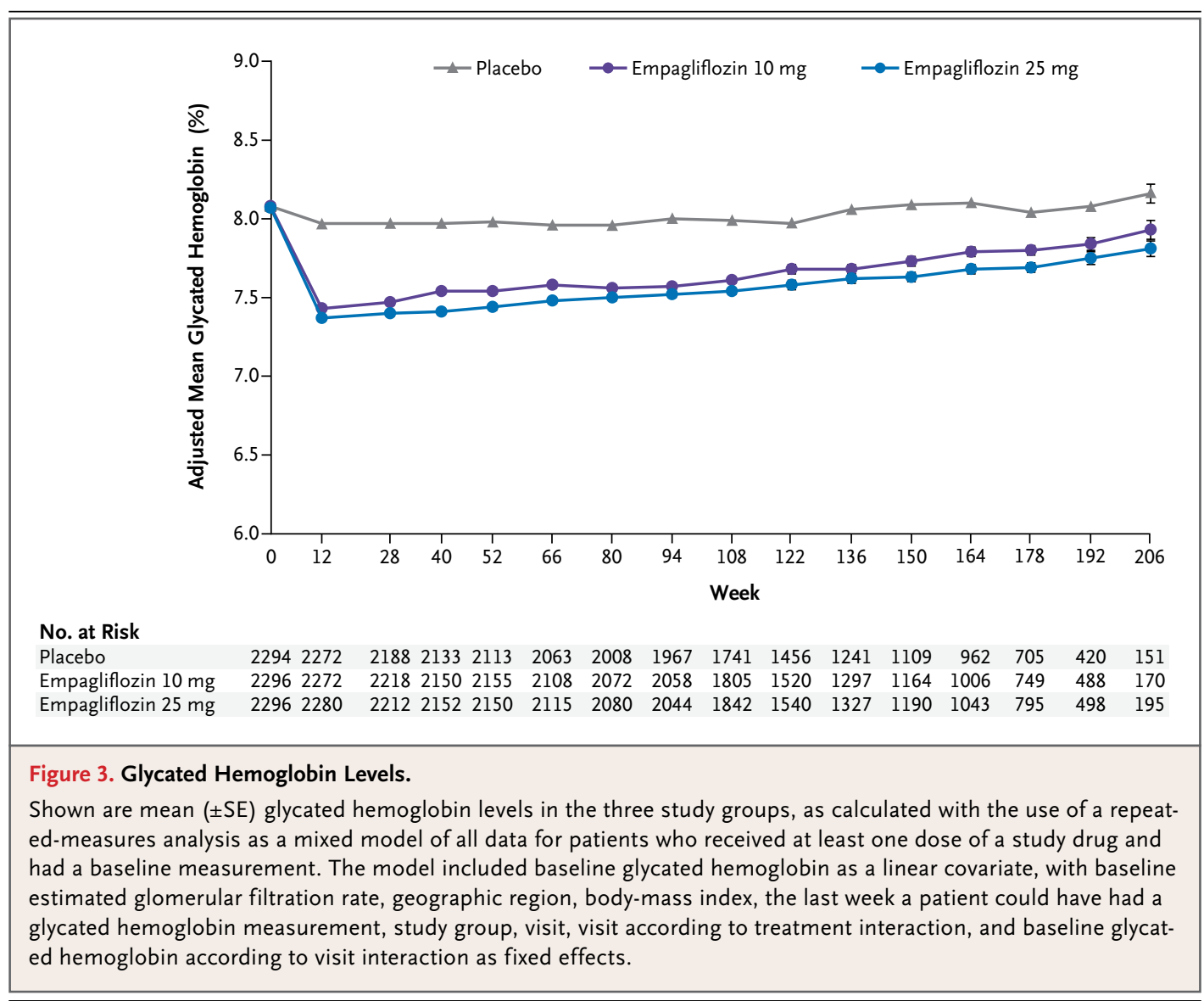

N ENGLJ MED 373;22 NEJM.ORG NOVEMBER 26, 2015 


\begin{tabular}{|c|c|c|c|c|}
\hline \multirow[t]{2}{*}{ Event } & $\begin{array}{l}\text { Placebo } \\
(\mathrm{N}=\mathbf{2 3 3 3})\end{array}$ & $\begin{array}{c}\text { Empagliflozin, } \\
10 \mathrm{mg} \\
(\mathrm{N}=2345)\end{array}$ & $\begin{array}{l}\text { Empagliflozin, } \\
25 \mathrm{mg} \\
(\mathrm{N}=2342)\end{array}$ & $\begin{array}{c}\text { Pooled } \\
\text { Empagliflozin } \\
(\mathrm{N}=4687)\end{array}$ \\
\hline & \multicolumn{4}{|c|}{ number of patients (percent) } \\
\hline Any adverse event & $2139(91.7)$ & $2112(90.1)$ & $2118(90.4)$ & $4230(90.2) \dagger$ \\
\hline Severe adverse event & $592(25.4)$ & $536(22.9)$ & $564(24.1)$ & $1100(23.5) \div$ \\
\hline \multicolumn{5}{|l|}{ Serious adverse event } \\
\hline Any & $988(42.3)$ & $876(37.4)$ & $913(39.0)$ & $1789(38.2) \dagger$ \\
\hline Death & $119(5.1)$ & $97(4.1)$ & $79(3.4)$ & $176(3.8) \mathbb{\int}$ \\
\hline $\begin{array}{l}\text { Adverse event leading to discontinuation of a } \\
\text { study drug }\end{array}$ & $453(19.4)$ & $416(17.7)$ & $397(17.0)$ & $813(17.3) \sqrt{1}$ \\
\hline \multicolumn{5}{|l|}{$\begin{array}{c}\text { Confirmed hypoglycemic } \\
\text { adverse event } 9\end{array}$} \\
\hline Any & $650(27.9)$ & $656(28.0)$ & $647(27.6)$ & $1303(27.8)$ \\
\hline Requiring assistance & $36(1.5)$ & $33(1.4)$ & $30(1.3)$ & $63(1.3)$ \\
\hline Event consistent with urinary tract infection $\|$ & $423(18.1)$ & $426(18.2)$ & $416(17.8)$ & $842(18.0)$ \\
\hline Male patients & $158(9.4)$ & $180(10.9)$ & $170(10.1)$ & $350(10.5)$ \\
\hline Female patients & $265(40.6)$ & $246(35.5)$ & $246(37.3)$ & $492(36.4) \div$ \\
\hline Complicated urinary tract infection*** & $41(1.8)$ & $34(1.4)$ & $48(2.0)$ & $82(1.7)$ \\
\hline Event consistent with genital infection $T^{\dagger} \dagger$ & $42(1.8)$ & $153(6.5)$ & $148(6.3)$ & $301(6.4) \dagger$ \\
\hline Male patients & $25(1.5)$ & $89(5.4)$ & $77(4.6)$ & $166(5.0) \dagger$ \\
\hline Female patients & $17(2.6)$ & $64(9.2)$ & $71(10.8)$ & $135(10.0) \dagger$ \\
\hline Event consistent with volume depletiontr & $115(4.9)$ & $115(4.9)$ & $124(5.3)$ & $239(5.1)$ \\
\hline Acute renal failure $\mathbb{\int}$ & $155(6.6)$ & $121(5.2)$ & $125(5.3)$ & $246(5.2) \int$ \\
\hline Acute kidney injury & $37(1.6)$ & $26(1.1)$ & $19(0.8)$ & $45(1.0) \div$ \\
\hline Diabetic ketoacidosis $₫ \emptyset$ & $1(<0.1)$ & $3(0.1)$ & $1(<0.1)$ & $4(0.1)$ \\
\hline 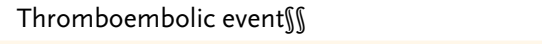 & $20(0.9)$ & $9(0.4)$ & $21(0.9)$ & $30(0.6)$ \\
\hline Bone fracture \|\| & 91 (3.9) & $92(3.9)$ & $87(3.7)$ & $179(3.8)$ \\
\hline \multicolumn{5}{|c|}{$\begin{array}{l}\text { Data are for patients who had one or more event and who had received at least one dose of a study drug. All events occurred within } 7 \text { days } \\
\text { after the last receipt of the study drug. } \\
\mathrm{P}<0.001 \text { for the comparison with placebo. } \\
\mathrm{P}<0.05 \text { for the comparison with placebo. } \\
\mathrm{P}<0.01 \text { for the comparison with placebo. } \\
\text { A confirmed hypoglycemic adverse event was a plasma glucose level of less than } 70 \mathrm{mg} \text { per deciliter ( } 3.9 \text { mmol per liter) or an event re- } \\
\text { quiring assistance. } \\
\text { The definition of urinary tract infection was based on } 79 \text { preferred terms in the Medical Dictionary for Regulatory Activities (MedDRA). } \\
\text { Percentages were calculated as the proportions of all men and all women with the event. } \\
\text { Complicated urinary tract infection was defined as pyelonephritis, urosepsis, or a serious adverse event consistent with urinary tract infection. } \\
\text { A breakdown of such events according to MedDRA preferred terms is provided in Table Sl3 in Section R in the Supplementary Appendix. } \\
\text { The definition of genital infection was based on } 88 \text { MedDRA preferred terms. Percentages were calculated as the proportions of all men } \\
\text { and all women with the event. } \\
\text { The definition of volume depletion was based on } 8 \text { MedDRA preferred terms. } \\
\text { The definitions of acute renal failure and thromboembolic event were based on } 1 \text { standardized MedDRA query for each. } \\
\text { The definition of ketoacidosis was based on } 4 \text { MedDRA preferred terms. } \\
\text { The definition of bone fracture was based on } 62 \text { MedDRA preferred terms. }\end{array}$} \\
\hline
\end{tabular}

placebo group. Our trial was designed to assess that the mechanisms behind the cardiovascular the specific effects of empagliflozin on clinical benefits of empagliflozin are multidimensional ${ }^{25}$ outcomes, and the mechanisms behind the ob- and possibly involve changes in arterial stiffserved benefits are speculative. As such, we infer ness, ${ }^{26,27}$ cardiac function, and cardiac oxygen 
demand (in the absence of sympathetic-nerve activation), ${ }^{26}$ as well as cardiorenal effects, ${ }^{21,26,28,29}$ reduction in albuminuria, ${ }^{20,30}$ reduction in uric acid, ${ }^{13-20}$ and established effects on hyperglycemia, weight, visceral adiposity, and blood pressure. ${ }^{13-20}$

Our trial provides data to support the longterm use of empagliflozin, as well as strong evidence for a reduction in cardiovascular risk. As observed in previous trials, genital infection was more common in patients treated with empagliflozin. Urosepsis was infrequent but reported in more patients treated with empagliflozin, although there was no increase in the overall rate of urinary tract infection, complicated urinary tract infection, or pyelonephritis. The proportions of patients with diabetic ketoacidosis, volume depletion, thromboembolic events, and bone fracture were low (ranging from $<1 \%$ for ketoacidosis and thromboembolic events to $5 \%$ for volume depletion) and similar in the empagliflozin groups and the placebo group. Concern has been expressed about the renal safety of inhibitors of sodium-glucose cotransporter 2 over time. However, the percentage of patients with acute renal failure (including acute kidney injury) was lower in the empagliflozin groups than in the placebo group, and renal function was maintained with empagliflozin.

In conclusion, patients with type 2 diabetes at high risk for cardiovascular events who received empagliflozin had significantly lower rates of the primary composite cardiovascular outcome and of death from any cause than did those in the placebo group when the study drugs were added to standard care.

Supported by Boehringer Ingelheim and Eli Lilly.

Dr. Zinman reports receiving consulting fees from Merck, Novo Nordisk, Sanofi Aventis, Eli Lilly, Takeda, AstraZeneca, and Janssen and grant support through his institution from Merck and Novo Nordisk; Dr. Wanner, receiving grant support from the European Foundation of Studies in Diabetes-Boehringer Ingelheim European Diabetes Research Programme; Dr. Lachin, receiving fees for serving on a steering committee from Merck, fees for serving on data monitoring committees from Gilead, Janssen, and Novartis, and consulting fees from AstraZeneca; Dr. Fitchett, receiving fees for serving on a data and safety monitoring board from Novo Nordisk and consulting fees from AstraZeneca, Sanofi, and Merck; Drs. Bluhmki, Hantel, Johansen, Woerle, and Broedel and Ms. Mattheus, being employees of Boehringer Ingelheim; and Dr. Inzucchi, receiving fees for serving on advisory boards from Merck, Janssen, Sanofi/Regeneron, Poxel, Boehringer Ingelheim, and Eli Lilly, fees for serving on data monitoring committees from Novo Nordisk and Intarcia, fees for serving on a steering committee from Lexicon, serving as an expert witness on behalf of Takeda in a patent suit, and receiving clinical-study drugs from Takeda, and receiving funding through his institution from Boehringer Ingelheim, Eli Lilly, Novo Nordisk, Abbott, Merck, and Sanofi. No other potential conflict of interest relevant to this article was reported.

Disclosure forms provided by the authors are available with the full text of this article at NEJM.org.

We thank the patients who participated in this trial and Elizabeth Ng and Wendy Morris of Fleishman-Hillard Group for their assistance in medical writing.
REFERENCES

1. Sarwar N, Gao P, Seshasai SR, et al. Diabetes mellitus, fasting blood glucose concentration, and risk of vascular disease: a collaborative meta-analysis of 102 prospective studies. Lancet 2010;375: 2215-22.

2. Beckman JA, Creager MA, Libby P. Diabetes and atherosclerosis: epidemiology, pathophysiology, and management. JAMA 2002;287:2570-81.

3. Di Angelantonio E, Kaptoge S, Wormser D, et al. Association of cardiometabolic multimorbidity with mortality. JAMA 2015;314:52-60.

4. Green JB, Bethel MA, Armstrong PW, et al. Effect of sitagliptin on cardiovascular outcomes in type 2 diabetes. $\mathrm{N}$ Engl J Med 2015;373:232-42

5. White WB, Cannon CP, Heller SR, et al. Alogliptin after acute coronary syndrome in patients with type 2 diabetes. $\mathrm{N}$ Engl J Med 2013;369:1327-35.

6. Scirica BM, Bhatt DL, Braunwald E, et al. Saxagliptin and cardiovascular outcomes in patients with type 2 diabetes mellitus. N Engl J Med 2013;369:1317-26. 7. Holman RR, Paul SK, Bethel MA, Matthews DR, Neil HA. 10-Year follow-up of intensive glucose control in type 2 diabetes. N Engl J Med 2008;359:1577-89.

8. Udell JA, Cavender MA, Bhatt DL, Chatterjee S, Farkouh ME, Scirica BM. Glucose-lowering drugs or strategies and cardiovascular outcomes in patients with or at risk for type 2 diabetes: a meta-analysis of randomised controlled trials. Lancet Diabetes Endocrinol 2015;3:356-66.

9. Department of Health and Human Services, Food and Drug Administration. Guidance for industry: diabetes mellitus - evaluating cardiovascular risk in new antidiabetic therapies to treat type 2 diabetes (http://www.fda.gov/downloads/drugs/ guidancecomplianceregulatoryinformation/ guidances/ucm071627.pdf).

10. Gallo LA, Wright EM, Vallon V. Probing SGLT2 as a therapeutic target for diabetes: basic physiology and consequences. Diab Vasc Dis Res 2015;12:78-89.

11. Grempler R, Thomas L, Eckhardt M, et al. Empagliflozin, a novel selective sodium glucose cotransporter-2 (SGLT-2) inhibitor: characterisation and comparison with other SGLT-2 inhibitors. Diabetes Obes Metab 2012;14:83-90.

12. Boehringer Ingelheim Pharmaceuti- cals. Jardiance (empagliflozin) tablets; prescribing information (http://bidocs .boehringer-ingelheim.com/BIWebAccess/ ViewServlet.ser?docBase=renetnt\&folder Path=/Prescribing+Information/PIs/ Jardiance/jardiance.pdf).

13. Häring HU, Merker L, Seewaldt-Becker E, et al. Empagliflozin as add-on to metformin plus sulfonylurea in patients with type 2 diabetes: a 24-week, randomized, double-blind, placebo-controlled trial. Diabetes Care 2013;36:3396-404.

14. Häring HU, Merker L, Seewaldt-Becker E, et al. Empagliflozin as add-on to metformin in patients with type 2 diabetes: a 24-week, randomized, double-blind, placebo-controlled trial. Diabetes Care 2014;37:1650-9.

15. Kovacs CS, Seshiah V, Swallow R, et al. Empagliflozin improves glycaemic and weight control as add-on therapy to pioglitazone or pioglitazone plus metformin in patients with type 2 diabetes: a 24-week, randomized, placebo-controlled trial. Diabetes Obes Metab 2014;16:147-58.

16. Roden M, Weng J, Eilbracht J, et al. Empagliflozin monotherapy with sitagliptin as an active comparator in pa- 
tients with type 2 diabetes: a randomised, double-blind, placebo-controlled, phase 3 trial. Lancet Diabetes Endocrinol 2013;1: 208-19.

17. Rosenstock J, Jelaska A, Frappin G, et al. Improved glucose control with weight loss, lower insulin doses, and no increased hypoglycemia with empagliflozin added to titrated multiple daily injections of insulin in obese inadequately controlled type 2 diabetes. Diabetes Care 2014;37:1815-23.

18. Rosenstock J, Jelaska A, Zeller C, Kim G, Broedl UC, Woerle HJ. Impact of empagliflozin added on to basal insulin in type 2 diabetes inadequately controlled on basal insulin: a 78-week randomized, doubleblind, placebo-controlled trial. Diabetes Obes Metab 2015 June 4 (Epub ahead of print).

19. Tikkanen I, Narko K, Zeller C, et al. Empagliflozin reduces blood pressure in patients with type 2 diabetes and hypertension. Diabetes Care 2015;38:420-8.

20. Barnett AH, Mithal A, Manassie J, et al. Efficacy and safety of empagliflozin added to existing antidiabetes treatment in patients with type 2 diabetes and chronic kidney disease: a randomised, doubleblind, placebo-controlled trial. Lancet Diabetes Endocrinol 2014;2:369-84.

21. Chilton RC, Tikkanen I, Cannon CP, et al. Effects of empagliflozin on blood pressure and markers of arterial stiffness and vascular resistance in patients with type 2 diabetes. Diabetes Obes Metab 2014 September 7 (Epub ahead of print).

22. Ridderstråle $M$, Andersen KR, Zeller C, Kim G, Woerle HJ, Broedl UC. Comparison of empagliflozin and glimepiride as add-on to metformin in patients with type 2 diabetes: a 104-week randomised, active-controlled, double-blind, phase 3 trial. Lancet Diabetes Endocrinol 2014;2: 691-700.

23. Zinman B, Inzucchi SE, Lachin JM, et al. Rationale, design, and baseline characteristics of a randomized, placebo-controlled cardiovascular outcome trial of empagliflozin (EMPA-REG OUTCOME). Cardiovasc Diabetol 2014;13:102.

24. Beyersmann J, Allignol A, Schumacher M. Competing risks and multistate models with R. New York: Springer, 2011.

25. Inzucchi SE, Zinman B, Wanner C, et al. SGLT-2 inhibitors and cardiovascular risk: proposed pathways and review of ongoing outcome trials. Diab Vasc Dis Res 2015; 12:90-100.

26. Cherney DZ, Perkins BA, Soleymanlou $\mathrm{N}$, et al. The effect of empagliflozin on arterial stiffness and heart rate variability in subjects with uncomplicated type 1 diabetes mellitus. Cardiovasc Diabetol 2014;13:28.

27. Cardoso CR, Ferreira MT, Leite NC, Salles GF. Prognostic impact of aortic stiffness in high-risk type 2 diabetic patients: the Rio de Janeiro Type 2 Diabetes Cohort Study. Diabetes Care 2013;36:3772-8.

28. Ronco C, McCullough P, Anker SD, et al. Cardio-renal syndromes: report from the consensus conference of the Acute Dialysis Quality Initiative. Eur Heart J 2010; 31:703-11.

29. Cherney DZ, Perkins BA, Soleymanlou N, et al. Renal hemodynamic effect of sodium-glucose cotransporter 2 inhibition in patients with type 1 diabetes mellitus. Circulation 2014;129:587-97.

30. Bakris GL, Molitch M. Microalbuminuria as a risk predictor in diabetes: the continuing saga. Diabetes Care 2014;37:867-75. Copyright @ 2015 Massachusetts Medical Society. 